\title{
Improvement of the Turbine Main Stop Valves with Flow Simulation in Erosion by Solid Particle Impact CFD
}

\author{
Z. Mazur, G. Urquiza, and R. Campos \\ Instituto de Investigaciones Eléctricas, Gerencia de Turbomaquinaria, Cuernavaca, Morelos, México
}

The flow field in a steam turbine main stop valve bypass valve (MSVBV) has been investigated by means of CFD simulations. Because the entire flow to the turbine during start ups is carried by the MSVBV it is subject to serious solid particle erosion problems and requires frequent replacement to avoid the catastrophic damage which can occurred when the MSVBV skirt eroded through causing large pieces of metal to be carried directly into the turbine. For some of the most important geometric parameters of the MSVBV, design recommendation have been made.

Keywords Erosion, Life extension, Main stop valve, Numerical simulation, Solid particles trajectories, Steam turbine

Solid particle erosion (SPE) of steam turbine components, such as nozzles, blades, radial spill-strips, and control valves, has been a problem of concern to utilities for several years as reported by Mazur et al. (1995) and Stástny et al. (1990).

It is generally agreed that erosion damage is caused by oxide scale exfoliation from boiler tubes and/or steam leads which becomes entrained in the steam flow to the turbine, causing erosion of the steam path and turbine components. Current exfoliation theory infers that the oxide particles spall off during unit shutdown, and become entrained in the steam during unit start up. Consequently, increasing the number of starts could increase the damage. In some units it is a normal practice of cycling the units to the extent of 200 starts/units/year which results in excessive solid particle erosion damage.

The MSVBV controls steam flow under full arc admission up to about 20 percent load. For hot and cold starts this amounts

Received 25 June 2002; accepted 1 July 2002.

Address correspondence to Zdzislaw Mazur, División de Sistemas Mecánicos, Instituto de Investigaciones Electricas, Apartado Postal 475, Centro Cuernavaca, Mor. 62000 Mexico. E-mail: mazur@ iie.org. $m x$ to approximately one and a half hours of operation per start respectively. In the $158 \mathrm{MW}$ steam turbines SPE damages the skirted section of the bypass valve. The severity of this problem is expected to continue to increase and more units will be subjected to cyclic operation. The situation is significant such that the availability of spare bypass valves has forced the management of the power plants to develop "in-house" bypass valve weld repair techniques. The concept of a bypass valve spare system has been conceived looking for methods of bypass valve improvement to accomplish their service life extension.

Particle-laden fluids are responsible for costly erosion problems that concern too much on steam turbine component life according to Humphrey (1990). CFD is thus used for flow optimisation purposes and to study or to understand the influence of various geometric parameters as reported by Sierra et al. (1997) and Mazur et al. (1999). For this analysis CFD has been considered as an effective tool since many configurations can be investigated at a low price.

\section{METHODOLOGY}

Solid particle erosion damage of bypass valve was observed to be concentrated at the skirted section but was also present in the spherical area of the bypass valve. In Figure 1 the found situation of damaged bypass valve by SPE is shown. The damage, if left to continue, can cause severe crack of the piece. Simulation of the flow represents a way to know how to avoid the damage by locating the regions of high impact before suggesting any modification to the present design.

Once knowing the flow pattern, modification to the geometry could be suggested and thus evaluated using the same CFD tool. In this paper we investigated the fluid flow through the valve which appears in Figure 2 using a 2D numerical model. The particular objective of this work is to study the flow through the valve looking for a reduction of the erosion process. In all series of results presented in this study we supposed a configuration of the bypass valve in the opened position. 


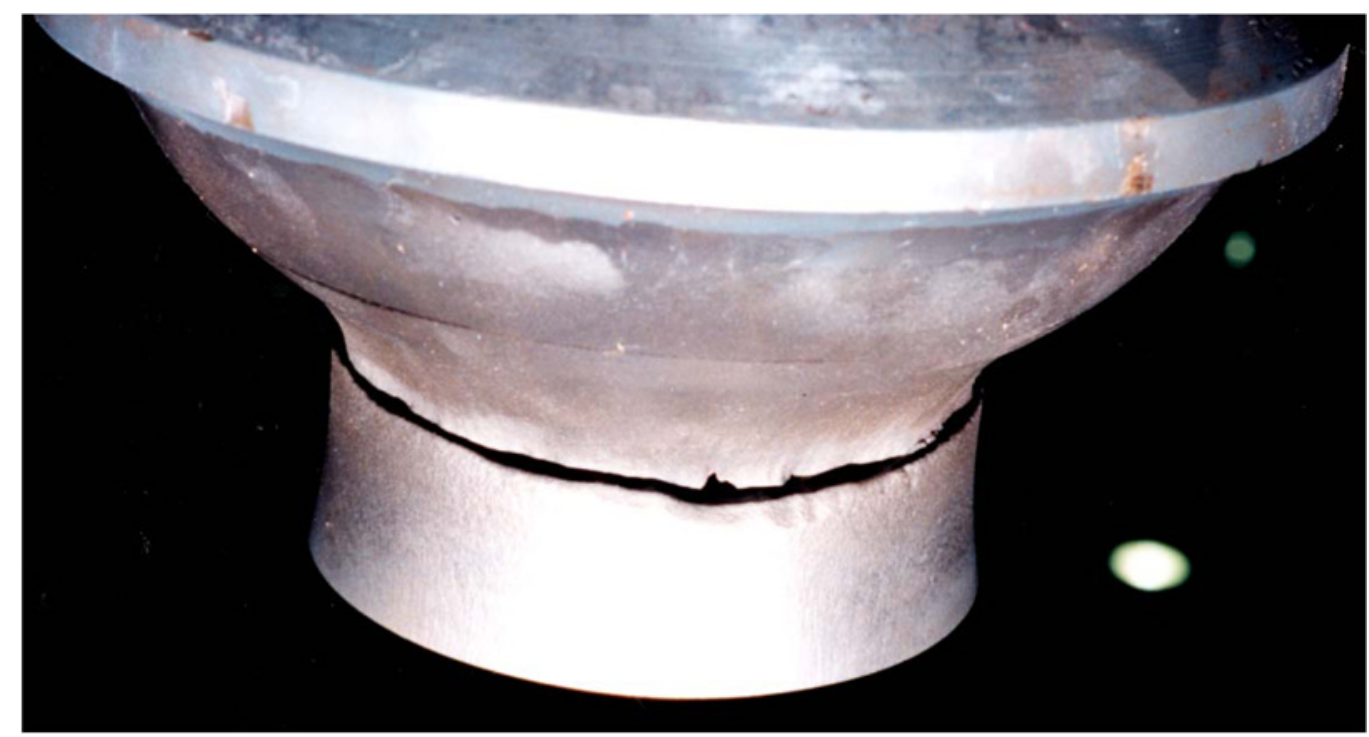

FIGURE 1

Bypass valve solid particle erosion damage.

\section{COMPUTATIONAL MODEL}

Numerical two-dimensional predictions have been carried out with the finite volume code FluentV5.5 using the $R N G$ model described by Hirsch (1990). From momentum and mass conser-

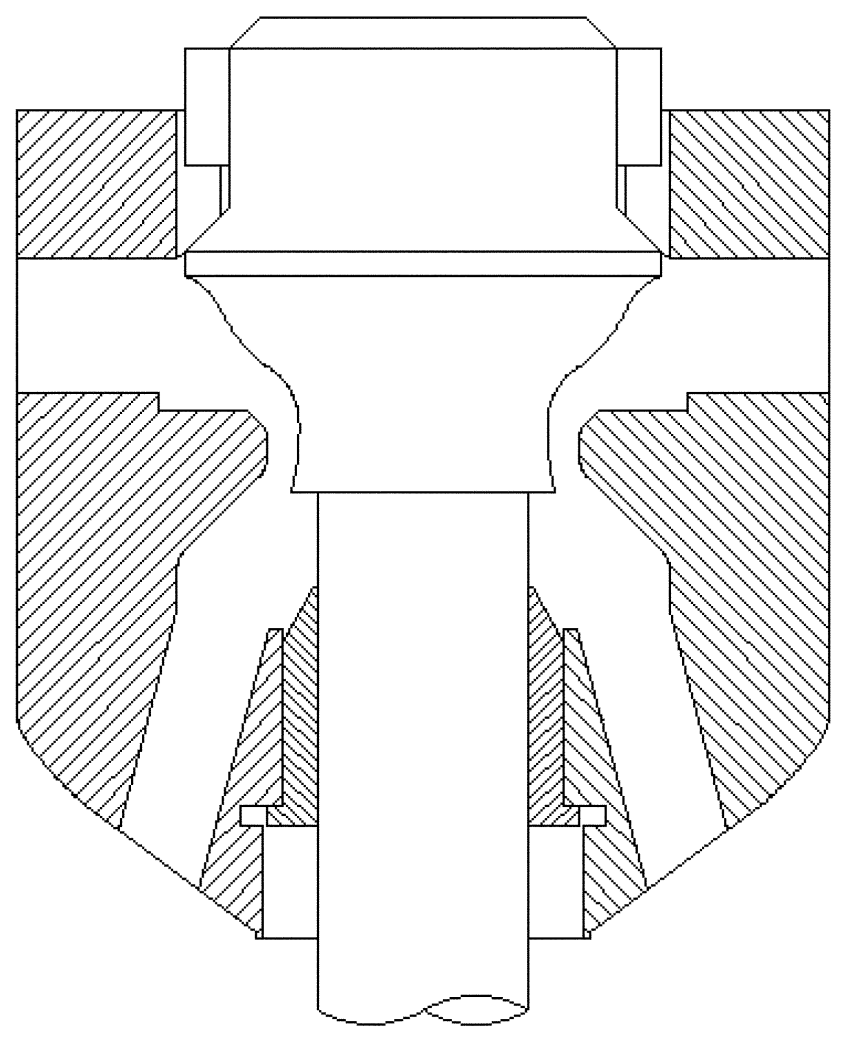

FIGURE 2

Diagrammatic arrangement of the bypass valve. vation laws, an equation system averaged on time is obtained. The system is closed to resolve the momentum equation in one point with the help of models for turbulence.

\section{Governing Equations}

The mass conservation equation, expressed as:

$$
\frac{\partial}{\partial x_{i}}\left(\rho u_{i}\right)=0
$$

plus the momentum balance equation:

$$
\frac{\partial}{\partial x_{i}}\left(\rho u_{i} u_{j}\right)=-\frac{\partial P}{\partial x_{i}}+\mu \frac{\partial}{\partial x_{j}} \frac{\partial u_{i}}{\partial x_{j}}-\frac{\partial}{\partial x_{j}}\left(\overline{\rho u_{i}^{\prime} u_{j}^{\prime}}\right)+\rho g_{i}
$$

where $x_{i}, u_{i}, \rho, P, g_{i}$ and $\mu$ represent the spatial co-ordinate in the $i$ direction, the velocity in the $i$ direction, the density, the pressure, the acceleration due to gravity and the dynamical viscosity. The $R N G$ model is based on the Boussinesq (1897) assumption, which relates the tensor stresses to the main strain of velocity as follows:

$$
\overline{u_{i}^{\prime} u_{j}^{\prime}}=\mu_{t}\left(\frac{\partial u_{i}}{\partial x_{j}}+\frac{\partial u_{j}}{\partial x_{i}}\right)-\frac{2}{3} \delta_{i j} k
$$

where $k=\frac{1}{2}\left(\overline{u_{i}^{\prime} u_{i}^{\prime}}\right)$ represents the turbulent kinetic energy and $\mu_{t}$ is the turbulent viscosity, which is related to $k$ and to the rate of energy dissipation $\varepsilon$ :

$$
\mu_{t}=C_{\mu} \frac{k^{2}}{\varepsilon}
$$


TABLE 1

Constant Values of Models for Turbulence

\begin{tabular}{lcccc}
\hline Model & \multicolumn{5}{c}{$R N G$} \\
\hline Constant & $\alpha$ & $C_{\mu}$ & $C_{1 \varepsilon}$ & $C_{2 \varepsilon}$ \\
Value & 1.39 & 0.0845 & 1.42 & 1.68 \\
\hline
\end{tabular}

$C_{\mu}$ is a model constant whose value is given in Table 1. Also, the dynamic viscosity together with the eddy viscosity are used in the description of an effective viscosity:

$$
\mu_{\text {eff }}=\mu+\mu_{t}
$$

Both $k$ and $\varepsilon$ were obtained through solving the following transport equations (Launder and Spalding, 1972):

$$
\begin{aligned}
\frac{\partial}{\partial x_{i}}\left(\rho u_{i} k\right) & =\frac{\partial}{\partial x_{i}}\left(\frac{\mu_{t}}{\sigma_{k}} \frac{\partial k}{\partial x_{i}}\right)+G_{k}+G_{b}-\rho \varepsilon \\
\frac{\partial}{\partial x_{i}}\left(\rho u_{i} \varepsilon\right) & =\frac{\partial}{\partial x_{i}}\left(\frac{\mu t}{\sigma_{\varepsilon}} \frac{\partial \varepsilon}{\partial x_{i}}\right)+C_{1 \varepsilon} \frac{\varepsilon}{k} G_{k}-C_{2 \varepsilon} \rho \frac{\varepsilon^{2}}{k}
\end{aligned}
$$

$G_{k}$ is generation of turbulent kinetic energy due to mean velocity gradientes (see Nomenclature, page 72). Values of $C_{1 \varepsilon}$, and $C_{2 \varepsilon}$, are also given in Table 1, whereas $G_{k}$ was calculated through:

$$
G_{k}=\mu_{t}\left(\frac{\partial u_{j}}{\partial x_{i}}+\frac{\partial u_{i}}{\partial x_{j}}\right) \frac{\partial u_{i}}{\partial x_{j}}
$$

The $R N G$ model considers an expression for the effective viscosity $\mu(l)$ given by the renormalization group theory presented by Yakhot and Orzag (1986):

$$
\mu(l)=\mu_{m o l}\left[1+\frac{3 A \varepsilon}{4 \mu_{m o l}^{3}}\left(l^{4}-l_{d}^{4}\right)\right]^{\frac{1}{3}} ;\left(l \geq l_{d}\right)
$$

where $l_{d}$ is an integral scale. An expression of equation (9) cast in terms of $k$ and $\varepsilon$ is used:

$$
\mu_{e f f}=\mu_{m o l}\left[1+\sqrt{\frac{C_{\mu}}{\mu_{m o l}}} \frac{k}{\sqrt{\varepsilon}}\right]^{2}
$$

using the constants values given in Table 1.

Any other constant employed in this work was assumed with the default value suggested in Fluent (1999). The RANS equation system is reduced into an algebraic system of equation, which is resolved in every cell using the SIMPLE algorithm for coupling the pressure to the momentum equations.

The computational domains that contain the details of both, the present and the suggested geometry of the bypass valve are represented by two grids, which were used for conducting the investigation; these are shown in Figures $3 a$ and $3 b$. Both grids are non-structured, and built in body fitted co-ordinates; the first with a number of 11714 cells, while the grid for the proposed configuration has a number of 11885 cells.
These numbers give a resolution of less than one $\mathrm{mm}$ per side for the cells in the region of the eroded rotor. Coarser grids were used to prove independence of grid.

\section{Boundary Conditions}

Boundary conditions were fixed from a set of flow conditions firstly calculated, which was obtained by using the thermal balance of the unit. A mass-flow inlet boundary was used for the incoming flow of steam water with a mass flow rate $=0.404 \mathrm{~kg} / \mathrm{s}$ and a pressure of $215700 \mathrm{~Pa}$ (see Figure 6). Operation conditions were declared to a pressure of zero such that the
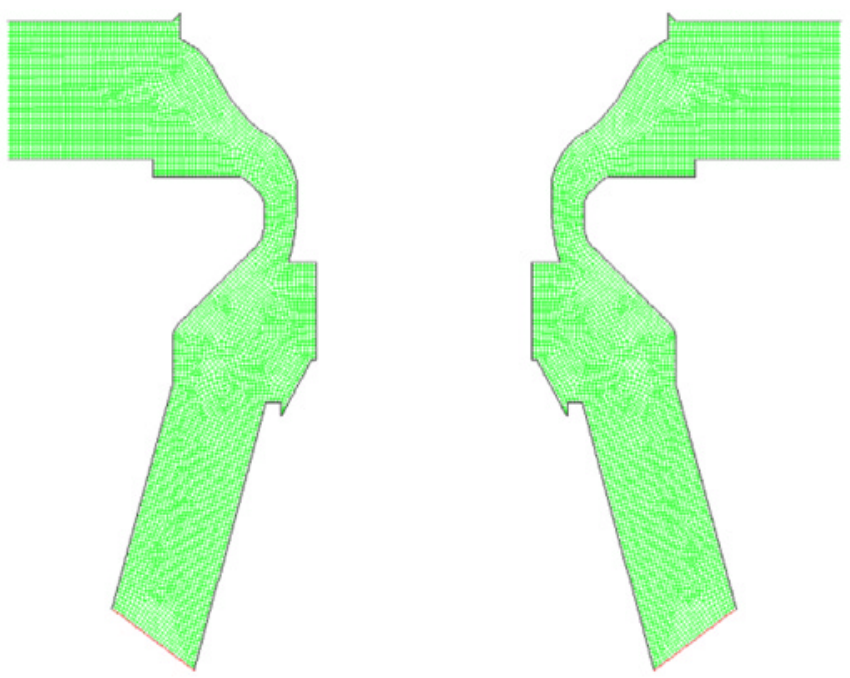

(a)
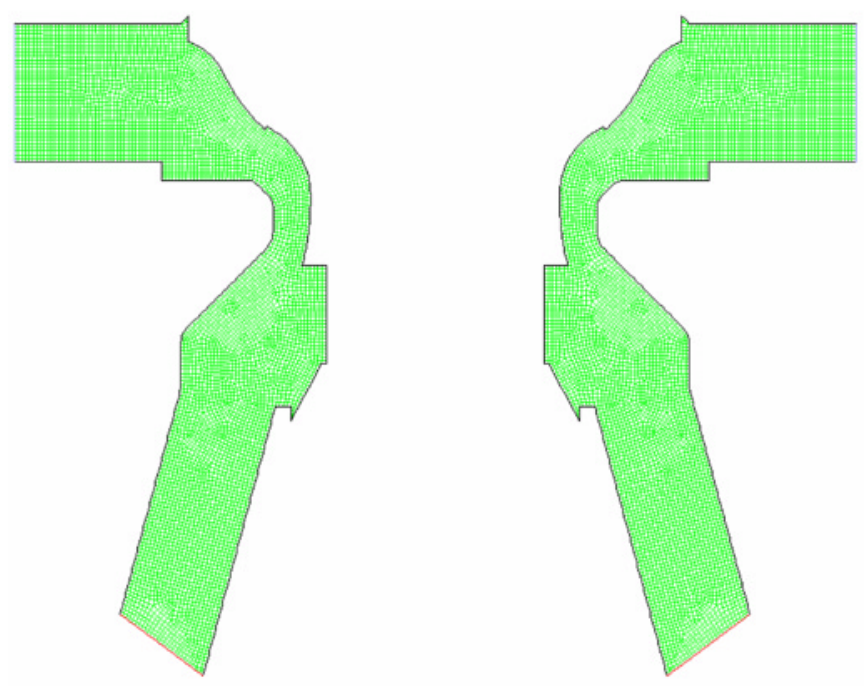

(b)

FIGURE 3

Computational grid of the bypass valve: (a) present configuration, (b) proposed configuration (not to scale). 
pressure declared for inlet and outlet represented gauged values. A pressure-inlet boundary was used as outlet boundary with the value of just above 1 atmosphere. The condition of no-slip was used in all the walls, and the velocity in the laminar sub-layer was calculated using the logarithmic law of the wall.
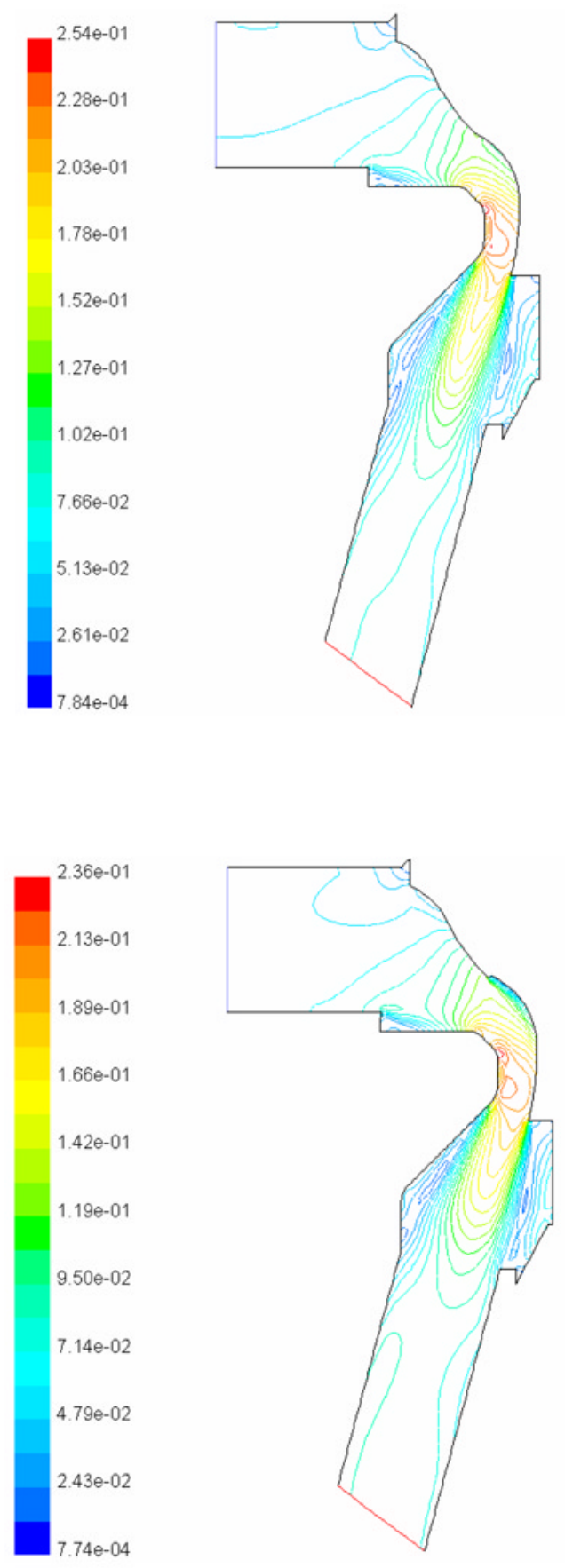

\section{RESULTS}

A numerical solution of the flow under the above considerations can be observed in Figure 4. The isolines of the Mach number are shown on this figure. For a pressure ratio $\varepsilon=$ 0.97 in the whole valve, a corresponding Mach number of the

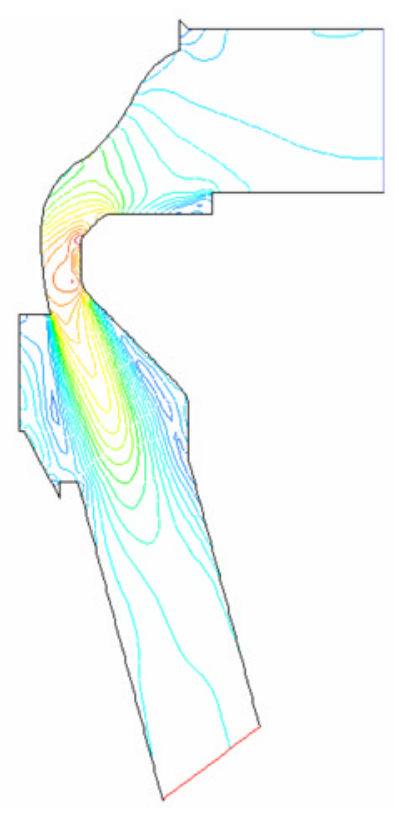

(a)

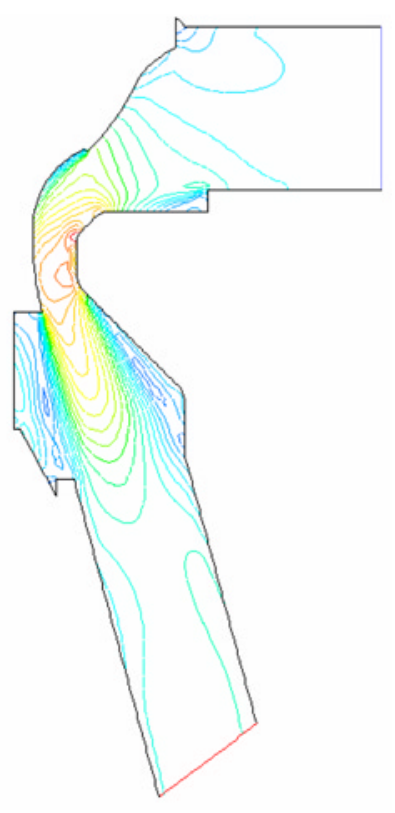

(b)

FIGURE 4

Isolines of the Mach number: (a) present configuration, (b) proposed configuration. 
isentropic flow $\mathrm{M}_{\mathrm{is}}=0.20$, but the local mach number values are considerably higher, as observed in this same figure.

As observed on Figure 5, velocities up to $1.78 \times 10^{2} \mathrm{~m} / \mathrm{s}$ are present in eroded zone. The erosion process is almost well understood to depend on the angle of particle impact, the velocity of particles and their composition, as well as the kind of material of the wall. The velocity of impact plays a particular main role on the erosion rate. Under this basis, any reduction of the velocity of impact will in principle lead to an effective reduction of the erosion. Two areas of recirculating (vortex region)
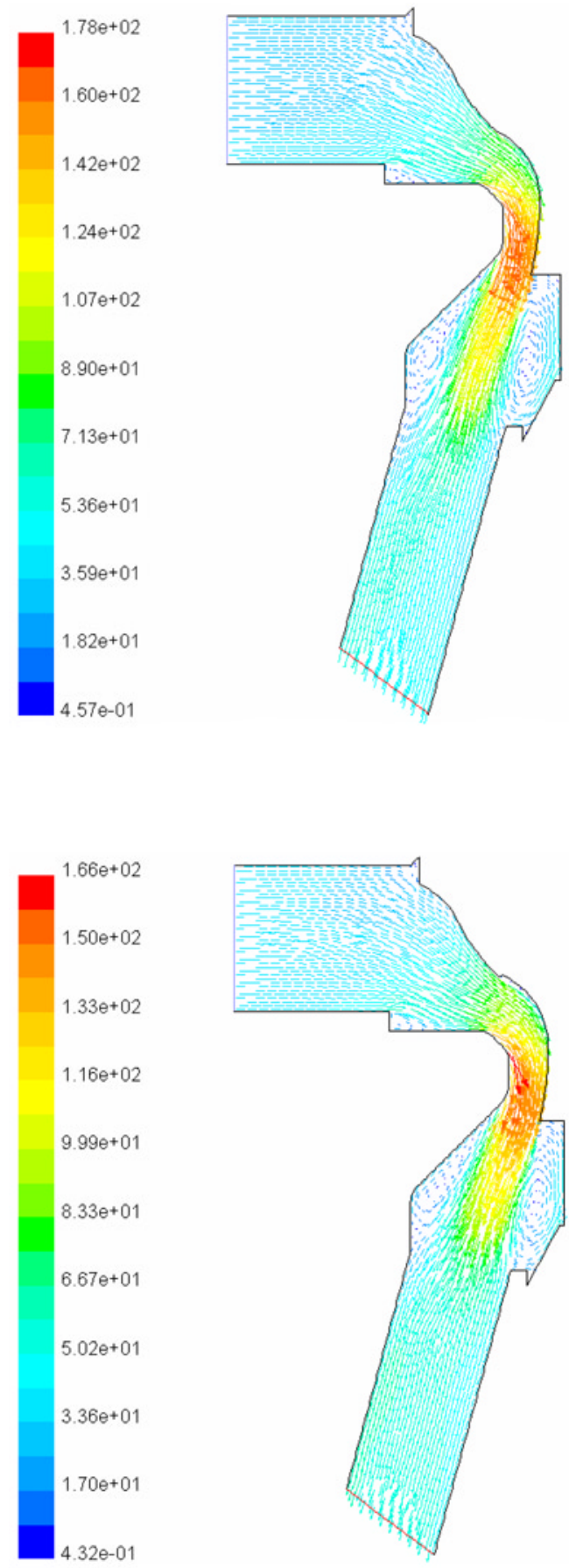

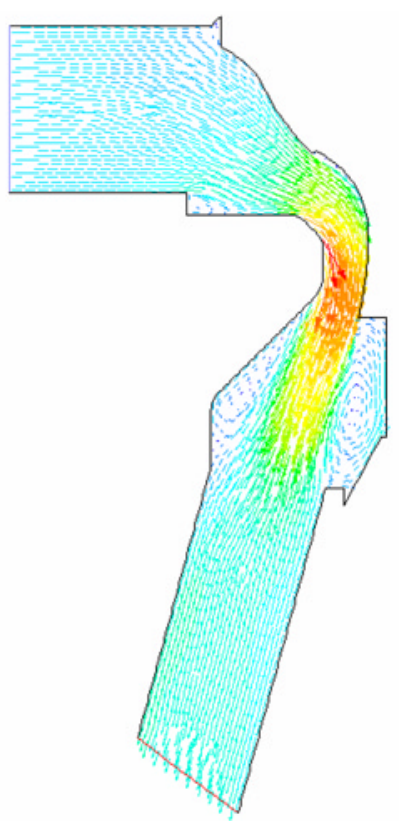

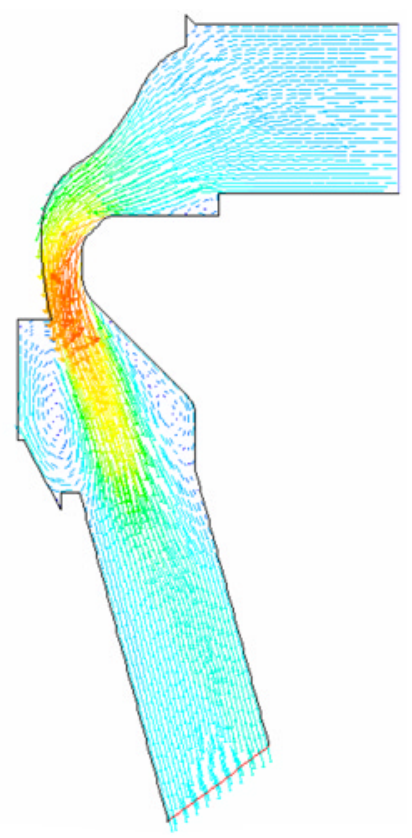

(a)

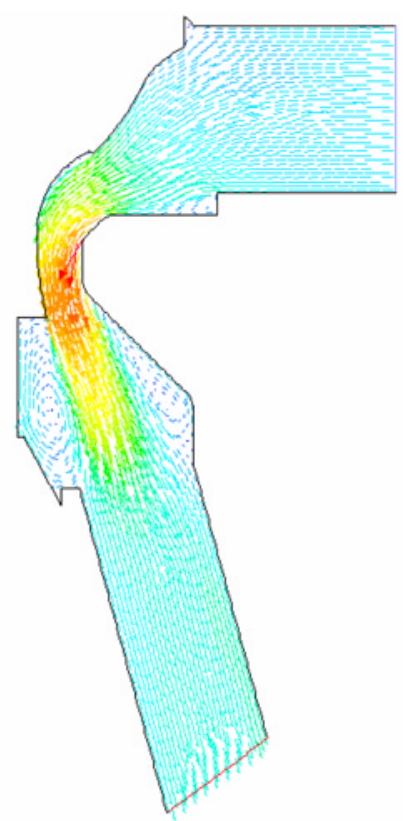

(b)

FIGURE 5

Velocity vectors: (a) present configuration, (b) proposed configuration. 
can be observed after the flow has passed the throat (minimum diameter).

In Figure 6, the streamline distribution is shown. The main difference between the present and the proposed configuration is in the outer flow layer in the diffuser. As already mentioned,
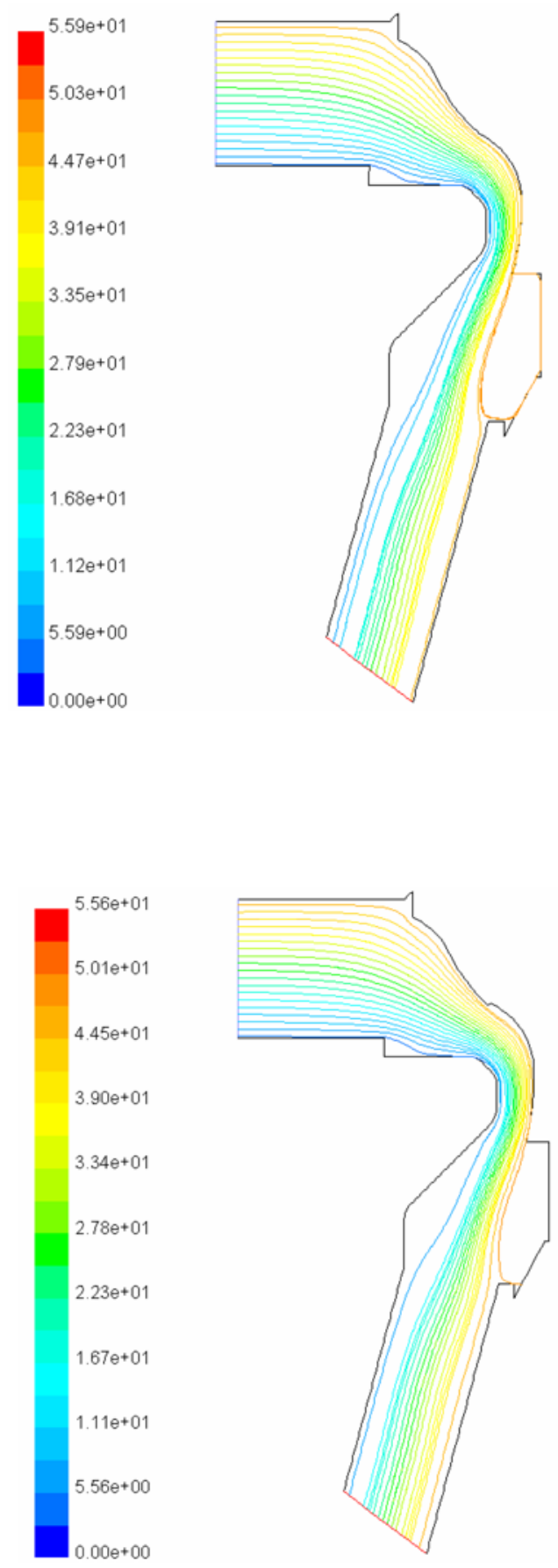

the present configuration is marked by the flow concentration close to the diffuser wall.

The opposite situation was created in the proposed valve configuration (Figures $5 \mathrm{~b}$ and $6 \mathrm{~b}$ ). Due to the step profile (off-set) forming on the valve skirted section the flow is separated from

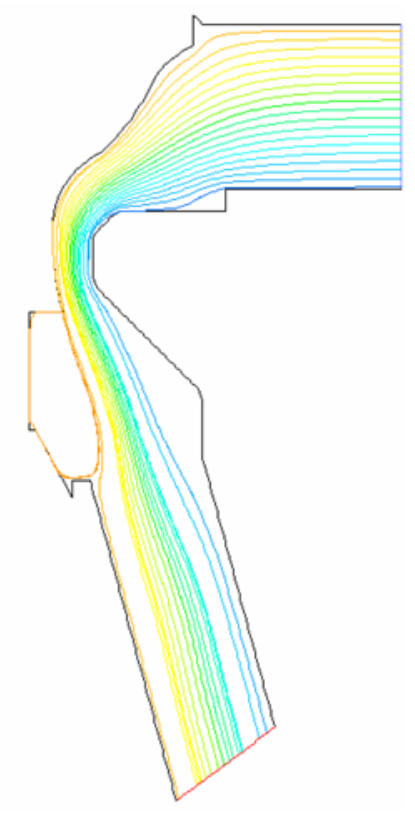

(a)

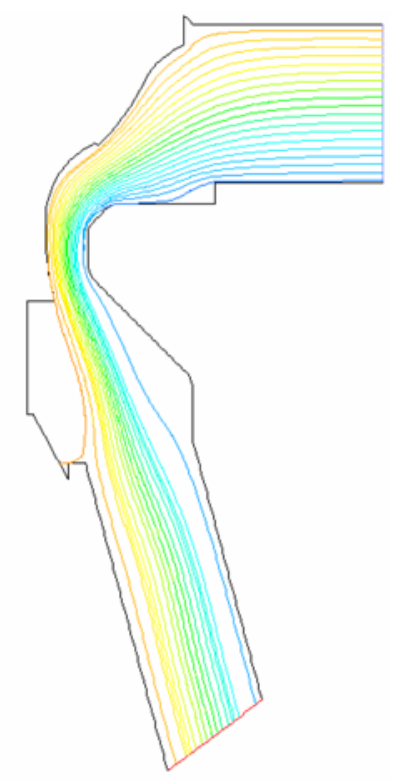

(b)

FIGURE 6

Streamline distribution: (a) present configuration, (b) proposed configuration. 
the valve surface in the zone of the maximum erosion rate. To estimate the influence of this situation on the valve erosion rate the trajectories of the solid particles were simulated.

The trajectories of particles in the zone of the valve skirted section for the present and proposed configuration is shown in Figures 7 and 8, respectively.
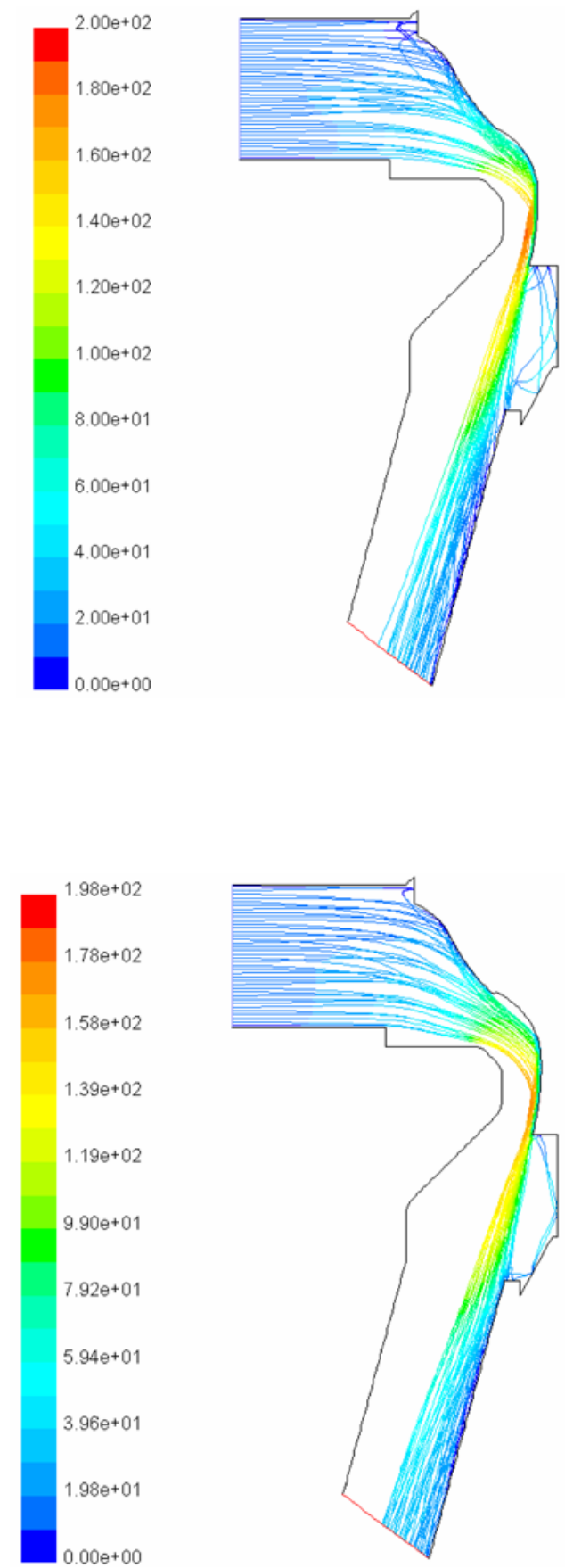

Due to step (off-set) formed on the valve skirted section, the flow (steam + solid particles) guided by valve surface before profile step, is separated (equidistant) from the skirted zone, resulting in changed particles trajectories, changed particles angle of impact on the valve surface and diminishing valve erosion problem (erosion rate).

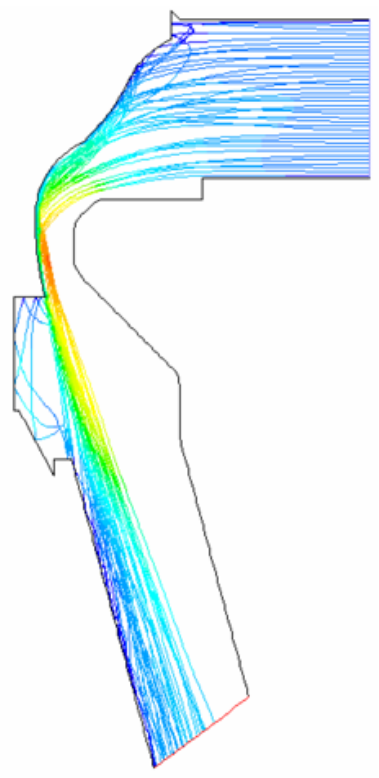

(a)

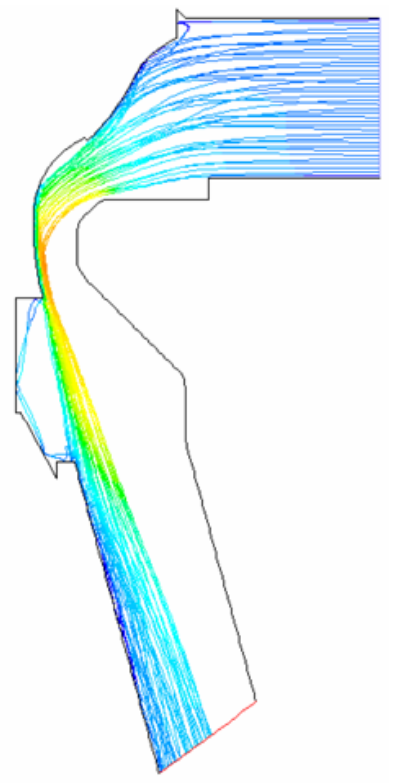

(b)

FIGURE 7

Particle tracks: (a) present configuration, (b) proposed configuration. 

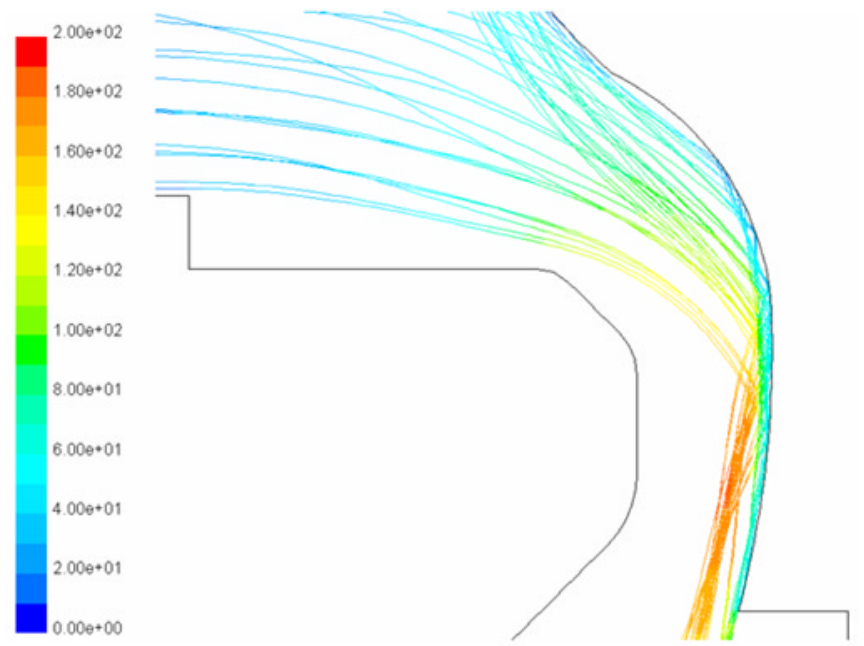

(a)
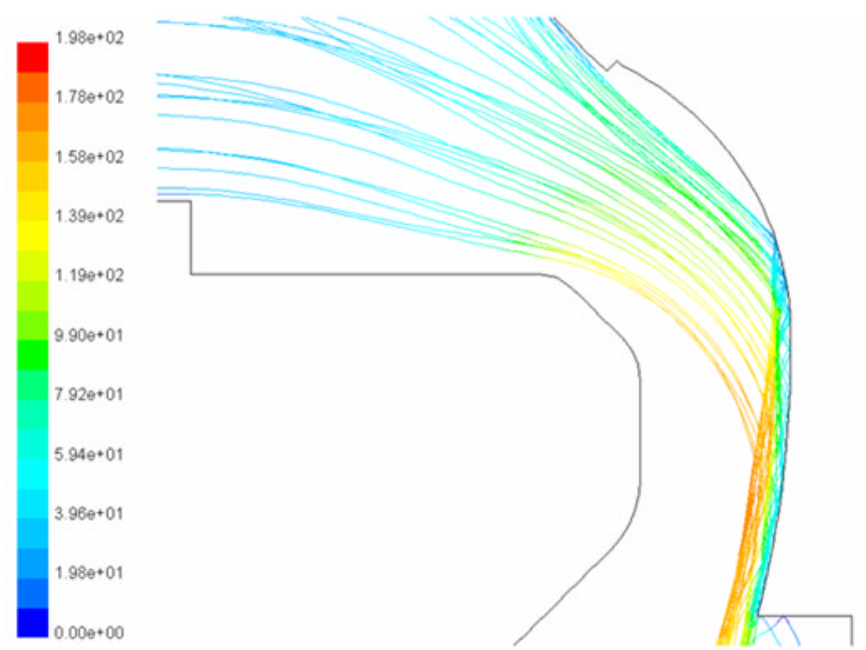

(b)

FIGURE 8

Particle tracks zoom: (a) present configuration, (b) proposed configuration.

\section{PRACTICAL IMPORTANCE}

The results obtained show that a numerical simulation can be used in a predictive manner to solve a real practical design problems. The simulation results may serve as an input in an early stage of the design procedure to identify regions where special surface treatment or design modification is necessary in order to increase the life time of the components. The particle-laden fluids are responsible for costly erosion problems that concern too much on steam turbine component life. Application of CFD for flow optimisation purposes and to study or to understand the influence of various geometric design parameters is an effective tool since many configurations can be investigated at a low price.

\section{CONCLUSIONS}

We verified the possibility of the 2D computation of the of the steam flow through a main stop valve bypass valve in a $158 \mathrm{MW}$ steam turbine, which is reported to be affected by erosion of internal parts. The study shows comparative figures obtained from two cases: present configuration (design condition) and proposed configuration, modifying the spherical area, which is reduced by $1 \mathrm{~mm}$ radially from the original design to reduce the erosion process on the latter. The numerical predictions showed a $6 \%$ reduction in the velocity of steam that impinges on the spherical area of the proposed configuration and renders better aerodynamic properties.

The results confirmed that is possible to reduce the valve erosion process, due to steam flow and hard particles velocity reduction and due to changing of particles trajectories and angle of impact.

The design modification presented here-in had been implemented during valve repair process and its operation performance will be monitored.

\section{NOMENCLATURE}

$\mathrm{A}, C_{\mu}, C_{1 \varepsilon}$ and $C_{2 \varepsilon} \quad$ turbulence model constants

$G_{k} \quad$ generation of turbulent kinetic energy due

$G_{b} \quad$ generation of turbulent kinetic energy

$g \quad$ acceleration due to gravity

$k \quad$ turbulent kinetic energy

$l \quad$ eddy length scale

$l_{d} \quad$ Kolmogorov dissipation scale

$P \quad$ pressure

$u \quad$ velocity

\section{Greek}

$\varepsilon$

$\mu$

$\mu_{t}$

$\mu_{\text {eff }}$

$\mu_{\text {mol }}$

$\rho$

$\sigma_{k}$ and $\sigma_{\varepsilon}$ rate of energy dissipation dynamical viscosity turbulent viscosity effective viscosity molecular viscosity density turbulent Prandtl numbers for $k$ and $\varepsilon$, respectively

\author{
Subscripts \\ $i$ \\ j
}

\section{REFERENCES}

Boussinesq, J. 1897. Théorie de L'écoulement Tourbillonmant et Tumultueux des Liquids Dans les Lits Rectilignes á Grandes Sections. Comptes Rendus de l'Académie des Sciences, T.72. 
Fluent V5.0. 1999. User's guide, vol. 3, Fluent Inc. Canterra Resource Park, 10 Cavendish Court, Lebanon, NH, EUA.

Hirsch, C. 1990. Numerical computation of internal and external flows, Vols. 1 and 2, John Wiley \& Sons, New York.

Humphrey, J. A. C. 1990. Fundamentals of fluid motion in erosion by solid particle impact: Review. International Journal of Heat and Fluid Flow 11:170-195.

Launder, B. E., and Spalding, D. B. 1972. Mathematical models of turbulence. Academic Press, London.

Mazur, Z., Cristalinas, V., and Kubiak, J. 1995. The methods of improving and emergency repair of steam turbine main stop valve bypass valve damaged by erosion. V Latin American Conference on Turbomachinery, Acapulco, Mexico, pp. 1-6.
Mazur, Z., Sierra, F., Urquiza, G., and Kubiak J. 1999. Modelling of the flow at the rotor disc in a geothermal turbine of 110 MW. Journal of Applied Thermal Engineering 21:599-611.

Sierra, F., Mazur, Z., Kubiak, J., Urquiza, G., Zúñiga, R., Mariño, C., and Hernández, A. 1997. Modelling of the flow at the last stage blade tenon in a geothermal turbine using RNG turbulence model. Journal of Applied Thermal Engineering 20:81-101.

Stástny, M. J., Brich, J., and Polansky, J. 1993. Numerical modelling of the steam flow through a balanced control valve, Modelling and Design in Fluid-Flow Machinery, Wydawnictwo IMP PAN, Gdansk, Poland, pp. 177-182.

Yakhot, V., and Orzag, S. A. 1986. Renormalization group analysis of turbulence: 1. Basic theory. Journal of Science in Computation 1:3. 

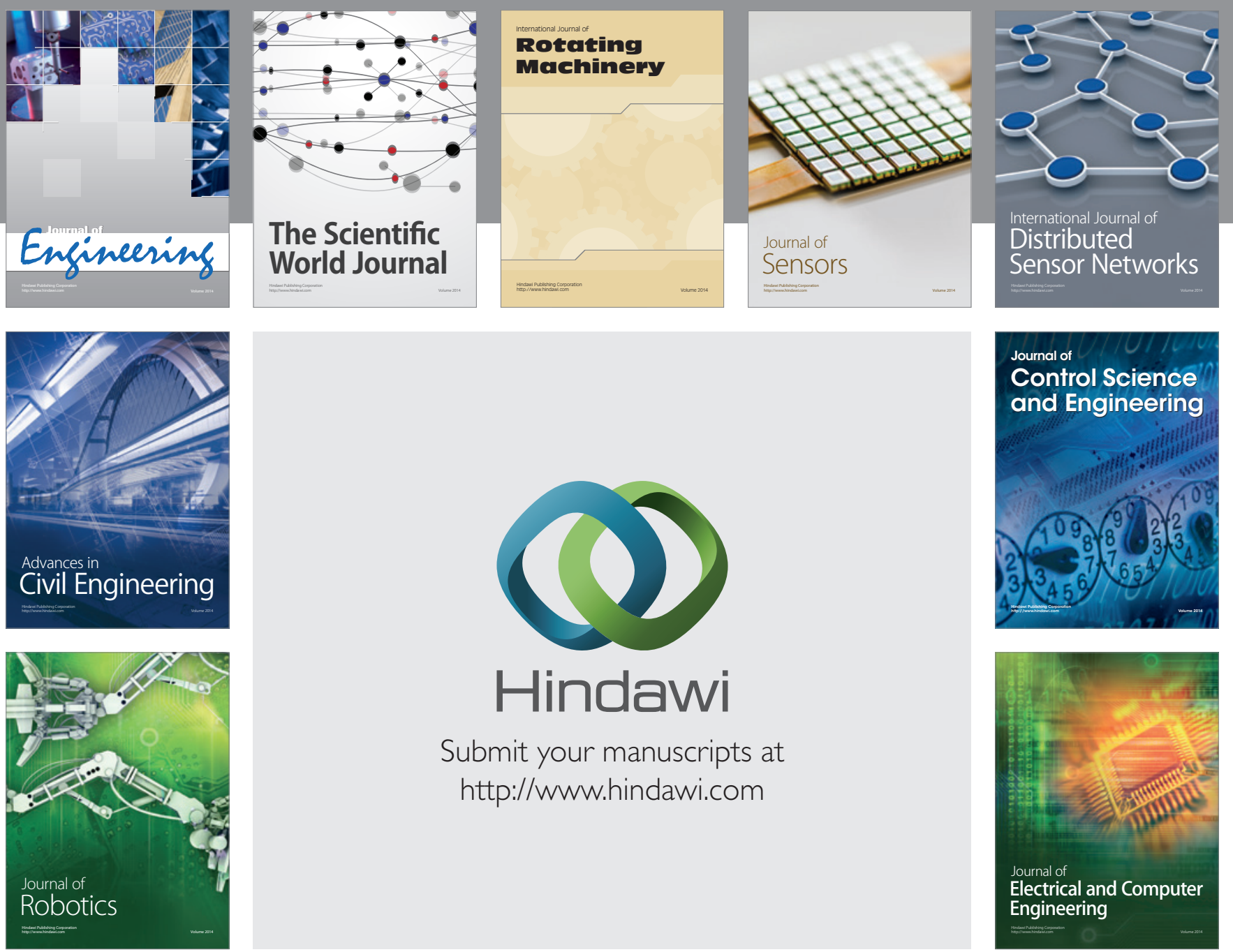

Submit your manuscripts at

http://www.hindawi.com
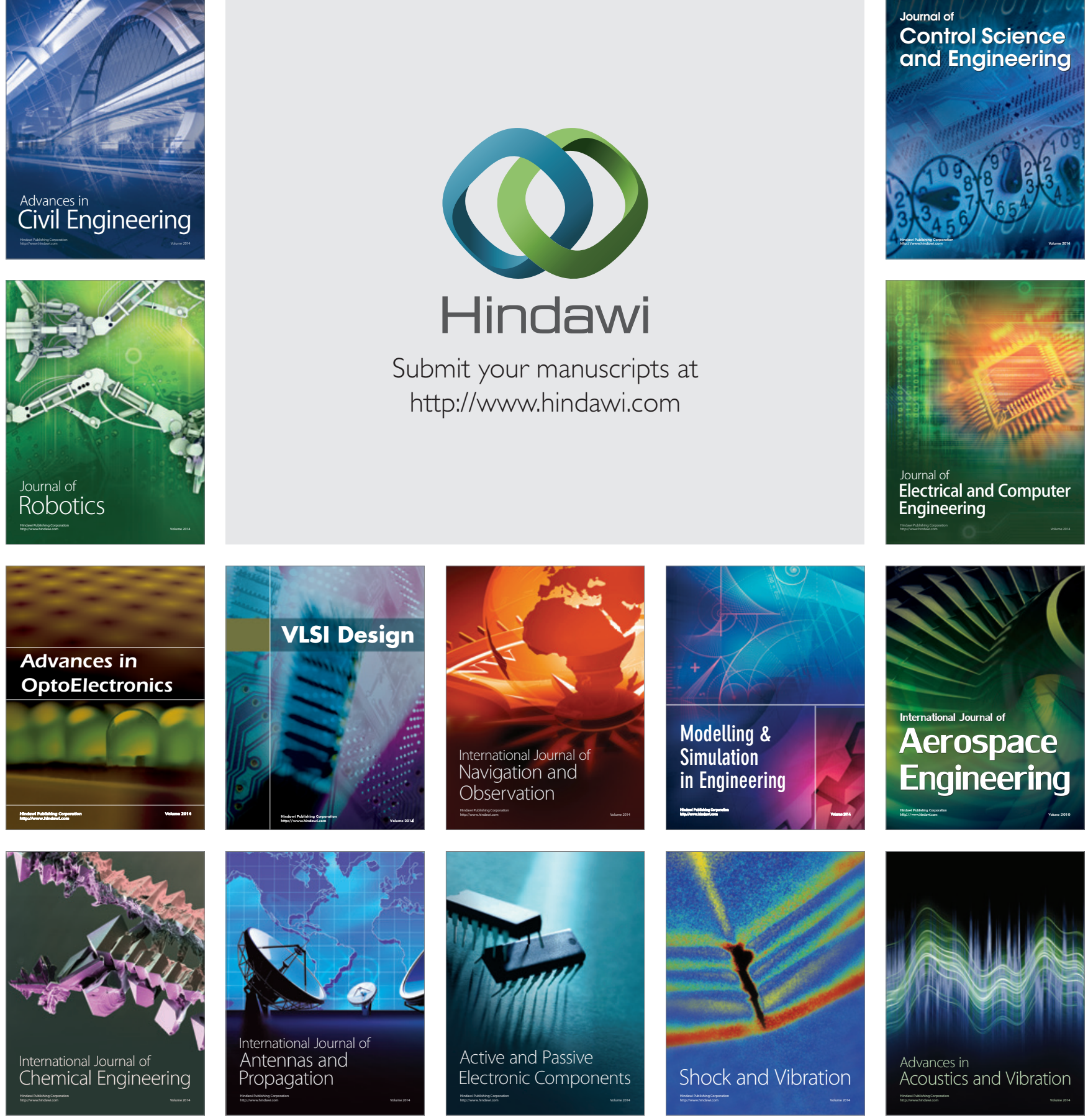